\title{
Yargıya yansıyan total kalça artroplasti ameliyatlarında tıbbi ve hukuki değerlendirme
}

\author{
Medical and legal evaluation in total hip arthroplasty surgeries \\ reflected in the judiciary
}

\author{
Serdar Şirazi ${ }^{1}$, İrfan Esenkaya ${ }^{2 *}$, İlhan Açıkgöz ${ }^{3}$ \\ ${ }^{1}$ Ortopedi ve Travmatoloji Uzmanı, Hukukçu, Arabulucu; Özel Avcılar Anadolu Hastanesi - Şahin Avukatlık Bürosu - \\ Akademi Arabuluculuk ve Tahkim Merkezi, İstanbul \\ Emekli Öğretim Üyesi, Ortopedi ve Travmatoloji Uzmanı, SANTE Tıp Merkezi, İstanbul \\ *Tıp Hukuku Yüksek Lisansı, MA \\ ${ }^{3}$ İstanbul Barosu Avukatı, Ortopedi ve Travmatoloji Uzmanı, Hastane ve Sağlık İşletmeleri Yöneticisi, Hukuk Doktoru, \\ Sağlık Hukuku Uzmanı - Özkaş Açıkgöz Hukuk Bürosu, İstanbul
}

\begin{abstract}
Total kalça artroplastisi; kullanılan malzemelerin çeşitliliği, ameliyat tekniklerinin farklı olması ve uygulanan hasta sayısının giderek artmasından dolayı hukuki ve cezai uyuşmazlık olarak ortopedi ve travmatoloji hekimlerinin karşısına daha sık çıkmaktadır. Ameliyattan sonra gelişebilen komplikasyonlar ve tıbbi uygulama hataları davaya yansıyarak ortopedi ve travmatoloji hekimlerinin önüne gelebilmektedir. Makalemizde söz konusu davalardan yüksek mahkemelere yansıyanların bir kısmı derlenmiş, gerek süreçle ilgili bilgi sahibi olunması, gerekse de uyuşmazlıklar çıkmadan önce yapılabilecek eylemler tespit edilerek ihtilafsız veya minimum ihtilaflı bir sürecin oluşması için katkıda bulunmak hedeflenmiştir.
\end{abstract}

Anahtar sözcükler: total kalça artroplastisi; komplikasyon; malpraktis; sağlık hukuku; tıp hukuku
Orthopedics \& Traumatology surgeons more commonly encounter legal and criminal disputes regarding total hip arthroplasty due to variety of materials used, the difference in surgical techniques and the increasing number of patients. Complications that may develop after surgery and medical practice errors may be reflected in the case and faced by these surgeons. In our article, some of the cases reflected in the high courts have been compiled, and it is aimed to contribute to the formation of a non-controversial or process with minimal dispute by determining both the information about the process and the indicating actions that can be taken before they arise.

Key words: total hip arthroplasty; complication; malpractice; health law; medical law

Sadece hekimleri ilgilendiren bir durumdan da öte, malzeme kullanılması ve kullanılan malzemelerin çeşitliliği de oluşan ihtilaflara konu olabilmektedir.

Yargının Adli Yargı ve İdari Yargı olarak iki büyük alt dalından söz etmemiz burada açıklayıcı olacaktır.

Adli Yargı, Ceza Mahkemeleri ve Hukuk Mahkemeleri olarak ayrılmaktadır. Ceza Mahkemeleri kişinin veya kişilerin konusu suç teşkil eden eylemlerinin yargılandığı yerdir. Hukuk Mahkemeleri de kişiler arasında özel ilişkilerden kaynaklanan uyuşmazlıkların çözüldüğü mahkemelerdir. Adli Yargı yüksek Mahkemesi Yargıtay'dır.

İdari Yargı kamuyu ilgilendiren uyuşmazlıkların çözüldügü yargı çeşididir. İdari yargının yüksek Mahkemesi Danıştay'dır.

iletişim / Contact: Dr. Serdar Şirazi • E-posta / E-mail: drserdarsirazi@yahoo.com

ORCID iD: Serdar Şirazi, 0000-0002-2155-1894 • İrfan Esenkaya, 0000-0002-7321-0012 • İlhan Açוkgöz, 0000-0002-5511-0341

Geliş / Received: 27 Eylül 2021 • Kabul / Accepted: 4 Ekim 2021 
Makalemiz için yapılan araştırmada yargıya yansıyan yaklaşık 1180 protez vakasına rastlanmış ve tanıtıcı özellikte olanlar dâhil edilerek detaylı olarak incelenmiştir. Bu sayede gerek süreçle ilgili bilgi sahibi olunması, gerekse de uyuşmazlıklar çıkmadan önce yapılabilecek eylemlerin tespiti sayesinde ihtilafsız veya minimum ihtilaflı bir sürecin oluşması için katkıda bulunmak hedeflenmiştir.

\section{Örnek Olgu 1}

Davacı; "geçirdiği kaza sonrası götürüldüğü davalı hastanede film çekildikten sonra doku zedelenmesi teşhisi konulduğunu, istirahat etmesine rağmen ağrıları dinmeyince başka sağlık kuruluşuna başvurduğunu ve burada ilk teşhisin hatalı olduğunun ve femur kırı̆̆ı (dosyada belirtilmemekle birlikte femur boyun kırığı olduğu düşünülmekte) nedeniyle acil ameliyat olması gerektiğinin anlaşıldı̆̆ını, total kalça protezi ameliyatı yapıldığııı" ifade ederek maddi manevi gördüğü zararına istinaden tazminat talebinde bulunularak dava açılmış. ${ }^{[1]}$

Mahkemece, Adli Tıp Kurumu'nun raporunda geç teşhis ile uygulanan tedavi arasında illiyet (nedensellik) bağı bulunmadığı belirtilerek ilk tanıyı koyan hekime kusur verilmemiş ve ilk derece mahkemesi bu karara istinaden davayı reddetmiş. ${ }^{[1]}$

Davacı tarafından karara itiraz edilmesi üzerine yüksek mahkeme hekimin hasta ile olan hukuki ilişkisinin vekalet sözleşmesine dayandığını, hekimin sorumluluğunun genel olarak işçinin sorumluluğuna ilişkin kurallara özdeşleştirilebileceğini belirterek vekilin (hekimin) işçi gibi özenle davranmak zorunda olup, en hafif kusurundan bile sorumlu olduğunu (Borçlar Kanunu'nun 320/1 ve 321. Md.) ${ }^{[2]}$, bu nedenle, doktorun meslek alanı içinde olan bütün kusurlarının, hafif de olsa sorumluluğun unsuru olarak kabul edilmesi gerektiğini belirtmiştir. ${ }^{[1]}$

Yüksek mahkeme, doktorun hastasının zarar görmemesi için mesleki tüm şartları yerine getirmesi gerektiğini, hastanın durumunu tıbbi açıdan zamanında ve gecikmeksizin saptayıp, somut durumun gerektirdiği önlemleri eksiksiz biçimde alması gerektiğini, uygun tedaviyi de yine gecikmeden belirleyip uygulamak zorunda olduğunu, asgari düzeyde dahi olsa, bir tereddüt doğuran durumlarda bu tereddüdünü ortadan kaldıracak araştırmalar yapmak ve bu arada da koruyucu tedbirleri almakla yükümlü olduğunun üzerinde durmuş. Ancak tıbbın gerek ve kurallarına uygun davranılmakla birlikte sonuç değişmemiş ise doktorun sorumlu olmayacağını belirtmiştir. ${ }^{[1]}$

Hükme dayanak teşkil eden Adli Tıp Kurumu raporunda davalı nezdinde çekilen grafide kırı̆̆ın belli olduğu ancak hastada mevcut çocuk felci rahatsızlığının doğurduğu sorunlar nedeniyle deneyimi olmayan pratisyen hekim tarafindan bunun fark edilemeyeceği, fark edilse de yine aynı tedavi yönteminin uygulanacak olması nedeniyle kusurun bulunmadığı mütalaa edilmiştir. ${ }^{[1]}$

Ancak mahkeme hekimin mesleki tecrübesizlikten dolayı geç teşhisin sabit olduğunu tespit etmiş ve üniversitelerden seçilecek öğretim üyelerinden oluşacak heyet ile bilirkişi raporunun yeniden alınmasına karar vererek hekim lehine verilen kararı bozmuş. ${ }^{[1]}$

Söz konusu uyuşmazlıkta, mahkeme; pratisyen hekimin polio sekeli tarafta meydana gelen femur boyun kırığını tespit edememesini veya konsülte etmemesini kusur olarak görüp gerekli tetkiklerin yapılmamasını özen yükümlülüğüne aykırı olarak değerlendirmiş ve bu konunun netlik kazanması için yeni bilirkişi tayini yoluna gidilmiştir.

\section{Örnek Olgu 2}

Femur boyun kırığına bağlı açılan bir dava: Ağustos 2008 tarihinde, düşme nedeniyle ................. Eğitim ve Araştırma Hastanesi Acil Servis Polikliniğine getirilen 1940 doğumlu hastanın yapılan muayene ve tetkiklerinde femur boyun kırığı tespit edildiği, 11.08.2008'de ameliyat edilerek bipolar kalça protezi uygulandığı, anestezi önerisiyle takip amaçlı cerrahi yoğun bakıma alındığı ve izlenimde ek problem olmayan hastanın 14.08.2008'de taburcu edildiği belirtilmiş. Sol kalçasında ağrı ve üzerine basamama şikayetleri devam eden hastanın, ilk ameliyattan yaklaşık iki yıl sonra, 15.09.2010 tarihinde, özel hastaneye müracaat ederek burada ortopedi ve travmatoloji uzmanı olan sanık tarafindan yapılan muayenede iç ve dış rotasyonların ağrılı olmasının protez gevşemesi olarak değerlendirildi$\breve{g i}$, yapılan kan tahlilleri ve çektirilen kemik sintigrafisi neticesi gevşemenin enfeksiyondan kaynaklanmadığı, önceki ameliyat tekniğinden kaynaklandığı sonucuna varılarak, 22.09.2010 tarihinde revizyon ameliyat hazırlığı yapıldığı ve sanık tarafından revizyon total kalça protezi ameliyatına alındığı ifade edilmiş. ${ }^{[3]}$

Sol kalçada ağrı şikâyetinin devamı üzerine, sanık tarafindan hasta 21.10.2010'da tekrar görülerek yapılan tetkiklerin ardından femoral stemin distale migre olduğunun tespit edilmesi üzerine 22.10.2010'da tekrar ameliyat edilmiş. Bu operasyonda femoral stem çıkarılarak, çimentolu olarak yerleştirilmiş. Takibi sonrası 25.10.2010' $\mathrm{da}$ taburcu edilmiş. ${ }^{[3]}$

íki gün sonra (27.10.2010 tarihinde) sol kalçada ağrı ve yürüyememe şikâyeti ile hasta yatırılarak yapılan tetkiklerin ardından tekrar ameliyat edilmiş; femoral kemik destekli uzun stemli, kablo ile takviyeli revizyon protez ameliyatı yapılmış ve hasta 15.11 .2010 'da taburcu edilmiş. ${ }^{[3]}$ 
Adli Tıp Kurumu 3. Adli Tıp İhtisas Kurulu'nca düzenlenen raporda sanık tarafindan yapılan 22.10.2010 tarihli 2. operasyon sırasında periprostetik kırık oluştuğu, bu durumun ameliyat sırasında meydana gelebilecek bir komplikasyon olduğu, önlem alınması gerektiği, hekim tarafından fark edilip edilmediğinin kayıtlarda bulunmadığı, fark edildi ise ne tür bir önlem alındığının kayıtlı olmadığından dolayı sanık tarafından yapılan eylemin tıp kurallarına uygun olmadığı ifade edilmiş. ${ }^{[3]}$

Yargıtay'ın ilgili dairesi de bu rapora istinaden hekim aleyhine karar vermiş olmakla birlikte çoğunluğa katılmayan üye şerh olarak; "Sanık savunmasında operasyon sonrası çekilen grafilerde kırığı tespit ettiğini ve bu hususta hasta ve yakınlarına bilgi verdiğini, hasta yakınlarının da önlem almasına müsaade etmeden onların zorlaması ile hastanın başka bir hastaneye sevkini sağladığını ileri sürdüğ̈̈ ve bu savunmanın ölenin oğlu tanık tarafindan da kısmen doğrulandı̆̆ı da nazara alınarak gerekli araştırmanın yapılıp ardından dosyanın Adli Tıp Kurumu Genel Kurulu'na gönderilerek, sanık tarafindan yapılan tüm ameliyat süreçleri, taburcu ve özel hastaneye sevk işlemleri de değerlendirmek suretiyle meydana gelen olayda sanığın tıp kurallarına uymayan davranışı olup olmadığının ve komplikasyon yönetiminde eksiklik bulunup bulunmadığının tespiti ile sonucuna göre hukuki durumunun tayin ve takdiri gerekir." ifadesi ile çoğunluk kararına katılmadığını belirtmişlerdir. Ancak mahkeme çoğunluk kararı gereği ilgili hekimi taksirle yaralama suçundan hüküm vermiş. ${ }^{[3]}$

Söz konusu örnek olguda; hekim hasta yakınlarına yaptığını ifade ettiği sözel açıklamayı yazılı halde epikriz raporunda belirtmiş olsaydı hüküm kendisi lehine olabilecekken durumu belirten yazılı belgenin dosya kapsamında olmaması hekimin mahkûm olmasına neden olmuştur. Kayıt tutma yükümlülüğün somut davada oldukça önemli olduğu görülmektedir.

\section{Örnek Olgu 3}

Hastaya (gelişimsel) kalça çıkığı rahatsızlığı nedeniyle total kalça protezi ameliyatı planlandığı ve 04.12.2007 tarihinde total kalça protezi planlanarak hastaneye yatışının yapıldığı, ortopedi ve travmatoloji uzmanı sanık tarafından ameliyata alındığı, ameliyatta kalça eklemine ulaşım sırasında ana femoral arter yaralanmasının geliştiği ve yaralanan damarın tamir edilmesi yerine o anki kanamayı durdurmak amacıyla damarın bağlandığı kayıtlardan anlaşılmıştır. ${ }^{[4]}$

Adli Tıp Kurumu bu eylemin tıp kurallarına uygun olduğunu belirtilmiş, ancak ameliyatın yapıldığı koşullarda o anda damar cerrahisi uzmanı temin edilmemiş olsa bile, ilk 6-8 saat içerisinde, kardiovasküler cerrahisinin bulunduğu merkeze sevk edilmesi gerektiği ve hekimin bunu yapmayarak zararın artmasına neden olduğunu, hastanın yaralanmasının, duyulardan veya organlardan birinin işlevinin yitirilmesi mahiyetinde olduğunu, meydana gelen netice dikkate alınarak hekimin taksirle yaralama suçunu yüksek mahkeme de oybirliğiyle onamış. ${ }^{[4]}$

Damar yaralanması ameliyatlar sırasında gerçekleşebilecekken yani komplikasyon olarak kabul edilebilecekken, komplikasyon sürecinin uygun yönetilmemesi tıbbi uygulama hatası olarak görülmekte ve ilgili hekime bu konuda açlan dava sonucunda da ceza verilebilmektedir.

\section{Örnek Olgu 4}

Hastanın, kalçasındaki kırık sebebiyle 17.10.2005 tarihinde ortopedi ve travmatoloji uzmanı tarafindan ameliyat edildiği, 20.10.2005 tarihli Sağlık Kurulu raporuna göre ameliyatta " $x$ " marka bir adet bipolar cup isimli malzeme ile " $x$ " marka bir adet femoral baş (head) isimli malzeme takıldığı, 17.10.2005 tarihli 2016 numaralı fatura ile bu malzemelerin mağdur kuruma satıldığı, sağlık kurulu raporuyla fatura içeriğinin birbirini doğruladığı, ancak hastanın rahatsızlığının devam etmesi üzerine 2006 yılı başında başka bir ortopedi ve travmatoloji uzmanı tarafından yapılan ikinci ameliyat ile mağdura takılmış olan protez malzemelerinin çıkarıldığı ve bu malzemelerin yerli üretim " $y$ " marka femoral baş isimli malzeme ile " $y$ " marka bipolar cup isimli malzeme olduğunun anlaşıldığı ve bu malzemelerin ise daha ucuz olduğunun saptandığı kayıtlardan anlaşılmıştır. ${ }^{[5]}$

Hastanın ithal malzemeler için " $x$ " firmasına 3.139.15 TL ödediği ancak ikinci ameliyat sonucunda malzemelerin daha düşük kalitedeki ucuz fiyatlı malzemeler olduğunun ortaya çıktığı, bahse konu şirketin yetkilisi olan sanıklar ile ilk ameliyatı yapan ortopedi ve travmatoloji uzmanı doktorun dolandırıcılık suçunu işledikleri iddia edilen olayda; 28.02.2006 tarihinde hastadan çıkarıldığı iddia edilen protezin iki yıl boyunca adı geçen doktor tarafından kayıtsız olarak muhafaza edilip 02.04.2008 tarihinde müfettişe teslim edildiği, suça konu malzemelerin mağdurdan çıkarıldığına dair bir tutanak ve tespitte bulunulmaması ve hastaların herhangi bir zararının bulunmaması ve tüm dosya kapsamına göre delil yetersizliği gerekçesiyle sanıklar hakkındaki beraat hükmü yüksek mahkeme tarafindan onanmış. ${ }^{[5]}$

Söz konusu dava kullanılan tıbbi malzeme ile alakaI olmakla birlikte total kalça protezi ameliyatlarında malzeme çeşitliliğinin fazla olması bu tarz uyuşmazlıkların çıkmasına da neden olabilmektedir. 


\section{Örnek Olgu 5}

İlgili dava taraf hatasından kaynaklanmaktadır. Hastanın devlet hastanesinde sol kalçasının ameliyat edilmesi gerekirken, sağ kalçasının ameliyat edilmesi sonucu sakatlığının artmasına ve bakıma muhtaç hale gelmesine neden olunduğundan bahisle uğranıldığı öne sürülen zararın tazmini istemiyle açılmıştır. ${ }^{[6]}$

Hastanın muayene ettirilmek suretiyle yaptırılan bilirkişi incelemesi sonucunda, davacının sol kalçasının total kalça proteziyle ameliyatı gerekirken sağ kalçasının ameliyat edildiğinin, ağrı ve şikayetlerinin arttığının, hareket yeteneğinin azaldığının, olay tarihinde bekar ve 38 yaşında olan davacının yaşamı boyunca başkalarının bakımına muhtaç hale geldiğinin saptandığı, bu durumda davacıya dava tarihine kadar yaptığı masraflarının yanında, bakımı için gerekli masraflarının da ödenmesi gerektiği, zarar hesabı için yaptırılan bilirkişi incelemesi sonucunda da maddi zararın 853.779.784 Türk Lirası olarak saptanmasına karşın istemle bağı kalınmasının zorunlu olduğu, davacının içinde bulunduğu durum ve olayın niteliğine göre manevi tazminat isteminin de kabulü gerektiği gerekçesiyle 2.000.000 Türk Lirası manevi, 4.000.000 Türk Lirası maddi zararın davalı idarece davacıya ödenmesine karar verilmiştir (dava 1995 yılında görüldüğünden talep edilen miktar eski Türk Lirası (TL) olarak geçmekte). ${ }^{[6]}$

Davalı idare, usul ve hukuka aykırı olduğu iddiasıyla kararı temyizen incelenip bozulmasını istemektedir. Yüksek mahkeme de kararın usul ve hukuka uygun olduğu, bozma nedeni bulunmadığını tespit ederek temyiz isteminin reddine ve anılan kararın onanmasına, oy birliğiyle karar verilmiş. ${ }^{[6]}$

\section{Örnek Olgu 6}

Davacının kalçasında ağrı şikâyeti ile devlet hastanesi ortopedi ve travmatoloji kliniğine başvurduğu, 26.8.1997 tarihinde yapılan sağ kalça total kalça protezi ameliyatı sonrasında, sağ kalçada hareket kısıtlılığı, sağ ayakta dorsifleksiyon kaybı ve şiddetli rahatsızlık veren ağrı tespit edildiğinden zararın tazmini istemiyle ameliyatı yapan doktor ve idare aleyhine dava açılmış. ${ }^{[7]}$

Yüksek Sağlık Şurasının 27-28.12.2001 tarihli kararıyla; ameliyatı yapan doktorun $2 / 8$ oranında kusurlu olduğuna karar verildiği, ilgili doktor aleyhine açılan davada, Asliye Hukuk Mahkemesinin kararıla "Kamu görevlilerinin yetkilerini kullanırken kişilere verdikleri zararlardan dolayı yalnız Devlet aleyhine dava açılacağına ilişkin Anayasa hükmü uyarınca, kamu görevlisi olan doktorun davacıya karşı sorumlu tutulamayacağı görülmüşstür.” Buna göre, davacıya uygulanan tıbbi müdahalede, idare elemanının 2/8 oranında kusuru bulunduğunun Yüksek
Sağlık Şurasınca belirlenmesi karşısında, idarenin sağlık hizmetini kusurlu işlettiği nedeniyle idare mahkemesinin idare lehine verdiği red kararını bozmuş. ${ }^{[7]}$

Davanın olduğu tarihte bulunan, ancak daha sonra kaldırılan Yüksek Sağlık Şura'sının hekime 2/8 oranında vermiş olduğu kusurun idareye yüklenebileceği gerekçesiyle tekrar yargılanmak üzere dosya yerel mahkemeye gönderilmiş.

Söz konusu durumlarda idare tazminata hükmedilince kamu görevlisine rücu edebileceğini de göz önünde bulundurulması gerekmektedir.

\section{Örnek Olgu 7}

Hastanın sol kalçada ağrı ve hareket kısıtlılığı şikayetleri ile devlet hastanesinde görevli ortopedi ve travmatoloji uzmanı tarafından muayene edildiği ve yapılan tetkikler sonucu 11/03/2009 tarihinde total kalça protez ameliyatı yapıldığı, ameliyattan bir gün sonra katılanın (hastanın) sol ayak bileği ve sol ayak parmaklarını oynatamadığı, bunun üzerine yeniden muayene edildiği, kalça çıkığı tespit edilen hastaya doktor tarafından kalça redüksiyonu yapıldığı kayıtlardan anlaşılmaktadır. ${ }^{[8]}$

Adli Tıp Kurumu Başkanlığı 2. İhtisas Kurulu'nun raporunun sonuç kısmında; ameliyat sonrası kalça protezi çıkığı oluşarak, sinire bası yaptığı ve sinir hasarına neden olduğunun anlaşıldığı, hastaya konulan sol koksartroz tanısı sonucu ameliyat endikasyonu bulunduğu, ameliyat sonrası ilk 24 saatte gelişen total kalça protezi çıkığı ve siyatik sinir paralizisinin bu tür ameliyatlardan sonra oluşabilen "komplikasyon" olarak nitelendirildiği, ancak her iki komplikasyonun birlikte görülmesi dikkate alındığında, ameliyat sonrası röntgen değerlendirilmesinde asetabuler komponentin muhtemel yerleşim probleminin olması ve erken çıkık sebepleri arasında sayılan protezin uyumsuz yerleştirilmesi gibi faktörlerin yeterince değerlendirilmediği, ameliyat sonrası güvenli bölge denilen hareket açıklığının tanımlanmaması ve gelişen siyatik sinir hasarı sonrası steroid uygulanmaması ve iyileşme yönünden fizik tedavi uygulanmaması gibi tedavi eksikliklerinin de bulunduğu, söz konusu durumların komplikasyon yönetiminde eksiklik olarak değerlendirildiği, ortopedi ve travmatoloji uzmanı doktorun bu yönden kusurlu bulunduğunu bildirilmiş. ${ }^{[8]}$

Yerel mahkeme hekim aleyhine taksirle başkasının vücuduna acı verme veya sağlığının ya da algılama yeteneğinin bozulmasına neden olmaktan ceza vermiş, karar temyiz edilmiş, üst mahkeme de ihmali davranışla görevi kötüye kullanma suçu kapsamında değerlendirilmesi gerektiğine karar vererek ilk derece mahkemenin verdiği kararı bozmuş. ${ }^{[8]}$ 
Söz konusu davada, total kalça protezi operasyonunda ameliyat esnasında yapılan eklem hareket açıklığı değerlendirmesinin yapılmadığı veya dosyada kayıtlı olmadığı, sinir arazı sonrası gerekli ilaç tedavisi ve fizik tedavinin uygulanmadığından dolayı hekime kusur verilmiş ve cezaya hükmedilmiş.

\section{SONUÇ}

Total kalça artroplastisi; kullanılan malzemelerin çeşitliliği, ameliyat tekniklerinin farklı olması, hasta yaş gruplarının çeşitliliği ve hasta sayısının giderek artmasından dolayı hukuki ve cezai uyuşmazlık olarak daha sık ortopedi ve travmatoloji hekimlerinin karşısına çıkmaktadır. Bu konuda hekimin hasta ile ilgili kayıtları tutması ve gelişebilecek komplikasyonları tıbbi olarak doğru yönetmesi ile ortaya çıkacak uyuşmazlıkların önüne geçilebilecektir.

\section{KAYNAKLAR}

1. T. C. Yargıtay 13. Hukuk Dairesi, Esas: 2014/10929, Karar: 2014/34504, Tarih: 05.11.2014.

2. Borçlar Kanunu: Kanun no, 818; Kabul tarihi, 22.04.1926; Yay. Resmi Gazete Tarihi, 29.04.1926; Yay. Resmi Gazete Sayısı, 359. https://www.tim.org.tr/files/downloads/mevzuat/ borclar_kanunu.pdf

3. T. C. Yargitay 12. Ceza Dairesi, Esas: 2016/2176, Karar: 2016/9149, Tarih: 31.05.2016.

4. T. C. Yargitay 12. Ceza Dairesi, Esas: 2014/7616, Karar: 2015/4593, Tarih: 11.03.2015.

5. T. C. Yargitay 15. Ceza Dairesi, Esas: 2016/863, Karar: 2016/5271, Tarih: 24.05.2016.

6. T. C. Danıştay 10. Daire, Esas: 1995/934, Karar: 1996/5933, Tarih: 10.10.1996.

7. T. C. Danıştay 10. Daire, Esas: 2004/6207, Karar: 2007/1653, Tarih: 04.04.2007.

8. T. C. Yargıtay 12. Ceza Dairesi, Esas: 2018/3113, Karar: 2020/5389, Tarih: 21.10.2020. 